\title{
Performance Evaluation of Diesel Engine Using Enriched Biogas: Review
}

\author{
H. S. Salave ${ }^{1,2}$, A. D. Desai ${ }^{3}$ \\ I(Department of Mechanical Engineering, M.E.S College of Engineering, S.P.Pune University, India) \\ ${ }^{2}$ (Research Scholar, Dr. D. Y. Patil Institute of Engineering and Technology, Pimpri,S.P.Pune University,India) \\ ${ }^{3}$ (Department of Mechanical Engineering, Shree Ramchandra College of Engineering Wagholi, S.P.Pune
}

University,India)

\begin{abstract}
Biogas produced from organic wastes is a potential alternative to the partial substitution of petroleum derived fuels because it is from renewable resources that are widely available. Biofuels derived from biomass are considered as good alternative to petroleum fuels. Biogas, a biomass derived fuel can be used in internal combustion (IC) engines. The main three objectives of this research was extraction of biomethane from biogas by using high pressure water scrubbing, conversion of diesel engine into biomethane engine. Injector nozzles were replaced by spark plugs and spark-ignition system with high-voltage was installed to ignite mixture. Biogas mixer system (venturi type) with electronically control was applied to replace diesel fuel system in order to supply gaseous fuel to the engine. In addition, engine management system with electronically controlled was used to control air-to-fuel ratio, ignition timing according to engine speed and load and The effect on performance of engine using biogas and diesel dual fuel operation is presented in this paper. In this paper, the important parameters of performance characteristics (such as: power output, thermal efficiency, fuel consumption and exhaust emission) of biogas-fueled C.I engine are studied and estimated with change of engine speed and load. The obtained results when operating with biogas are used to compare with that of diesel fuel under the same operating conditions.
\end{abstract}

Keywords - Organic waste, Biomass, Alternative Fuel, Biomethane Engine

\section{INTRODUCTION}

Today our society relies on gasoline as the primary fuel source for the automotive industry. Carbon dioxide emissions, produced in combustion, are believed to have damaging effects on the environment. Climate change may persist and available resources may run out if no actions are taken to decrease the use of fossil fuels. Gasoline prices are at record highs and will continue to rise as the demand for fuel and energy increases. Many experts believe that the solution to our problems is the renewable alternative energy source, biomethane [1]. Biomethane is a biofuel made from organic waste, created through anaerobic digestion. Using biomethane as a fuel source produces only water vapor and small amounts of carbon dioxide as products. This small amount of carbon dioxide will greatly decrease our current transportation pollution by reducing emissions. Several cars on the road today that use biomethane as fuel, show promise that these vehicles can be integrated into today's society[1]. Biogas upgrading and the production of biomethane nowadays is a state-of-the-art-process of gas separation. A number of different technologies to fulfil the task of producing a biomethane stream of sufficient quality to act as a vehicle fuel or to be injected into the natural gas grid are already commercially available and have proven to be technically and economically feasible. Nevertheless, intensive research is still in progress to optimize and further develop these technologies as well as to apply novel technologies to the field of biogas upgrading. All technologies have their own specific advantages and disadvantages and this review shows, that no technology is the optimal solution to each and every biogas upgrading situation. The right choice of the economically optimal technology is strongly depending on the quality and quantity of the raw biogas to be upgraded, the desired biomethane quality and the final utilization of this gas, the operation of the anaerobic digestion plant and the types and continuity of the used substrates as well as the local circumstances at the plant site. This choice is to be made by the planner and future operator and this report is worked out to act as a supporting guideline during the planning phase of a new biomethane production site[2]. Raw biogas can not be used directly in e.g. engines or heaters because of corrosion problems; the biogas needs to be cleaned. This cleaning incorporates $\mathrm{H} 2 \mathrm{~S}$ removal and removal of dust, water, halogenated hydrocarbons and siloxanes etc. This cleaned biogas can be used in engines for co-generation or in heaters. However, for use in vehicles it is generally accepted to upgrade the biogas, to natural gas like composition, also called biomethane, by means of $\mathrm{CO} 2$ removal (among others). In this way the upgraded biogas (biomethane) can be used for grid injection or can be used in standard light-duty or heavy-duty natural gas vehicles [3]. 


\section{PRESSURISED WATER SCRUBBING}

The absorbed gas components are physically bound to the scrubbing liquid, in this case water. Carbon dioxide has a higher solubility in water than methane and will therefore be dissolved to a higher extend, particularly at lower temperatures and higher pressures. In addition to carbon dioxide, also hydrogen sulphide and ammonia can be reduced in the biomethane stream using water as a scrubbing liquid. The effluent water leaving the column is saturated with carbon dioxide and is transferred to a flash tank where the pressure is abruptly reduced and the major share of the dissolved gas is released. As this gas mainly contains carbon dioxide, but also a certain amount of methane (methane is also soluble in water, but to a smaller extent) this gas is piped to the raw biogas inlet. If the water is to be recycled back to the absorption column it has to be regenerated and is therefore pumped to a desorption column where it meets a counter current flow of stripping air, into which the remaining dissolved carbon dioxide is released. The regenerated water is then pumped back to the absorber as fresh scrubbing liquid [2].

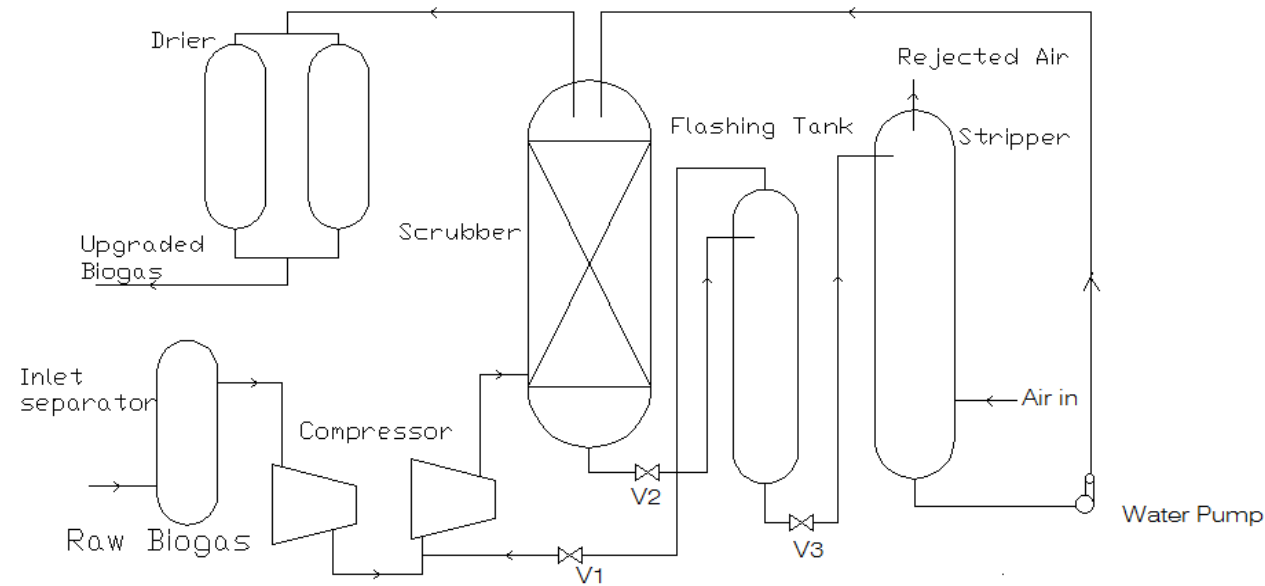

Fig 1. Water scrubbing biogas up gradation technique

The absorbed gas components are physically bound to the scrubbing liquid, in this case water. Carbon dioxide has a higher solubility in water than methane and will therefore be dissolved to a higher extend, particularly at lower temperatures and higher pressures. In addition to carbon dioxide, also hydrogen sulphide and ammonia can be reduced in the biomethane stream using water as a scrubbing liquid. The effluent water leaving the column is saturated with carbon dioxide and is transferred to a flash tank where the pressure is abruptly reduced and the major share of the dissolved gas is released. As this gas mainly contains carbon dioxide, but also a certain amount of methane (methane is also soluble in water, but to a smaller extent) this gas is piped to the raw biogas inlet. If the water is to be recycled back to the absorption column, it has to be regenerated and is therefore pumped to a desorption column where it meets a counter current flow of stripping air, into which the remaining dissolved carbon dioxides released. The regenerated water is then pumped back to the absorber as fresh scrubbing liquid[4].

\section{BIOMETHANE ENGINE}

The biogas-based-gasoline engine is contributing for economic development in rural area. Regularly, biogas engine is using for electric generator, water pump ... and normally operates at low engine speed conditions (around $1500 \mathrm{rpm}$ ). Therefore, the conversion biogas based- gasoline engine has low engine efficiency and generates low power output $(<20 \mathrm{~kW})$ compared to the original one (maximum power $>60 \mathrm{~kW}$ ). In order to get higher engine efficiency and higher power output, it required running engine at high-speed condition. However, the increase power output does not direct proportion to the engine speed or energy supply. Therefore, engine efficiency becomes worse at higher engine speed and increases tail pipe exhaust gas emissions. Biogas-based-diesel engine may be a suitable solution to overcome the concern problems [5].The biogas-based-diesel helps reduce consumption of fossil fuel in operation and reduce contribution of $\mathrm{CO} 2$ to the environment [6]. In addition, the application of high compression ratio spark-ignition biogas-engine for power generation will discard diesel-fuel dependence and has no soot in emission. So, the high-compression-ratiospark ignition- biogas-engine will overcome disadvantages of current conversion technologies [7, 8]. The main objective of this research is to develop technology to convert diesel engine to biogas engine operating at high compression ratio. The conversion engine will operate at compression ratio higher than normal gas engine and expecting to generate high performance and high efficiency. 


\section{MODIFICATION IN DIESEL ENGINE}

In order to convert diesel to biogas engine, the appropriate technologies are proposed to study as follow [5]:

1) Design and develop gas intake system

2) Design and develop ignition system

3) Design and manufacture engine management system

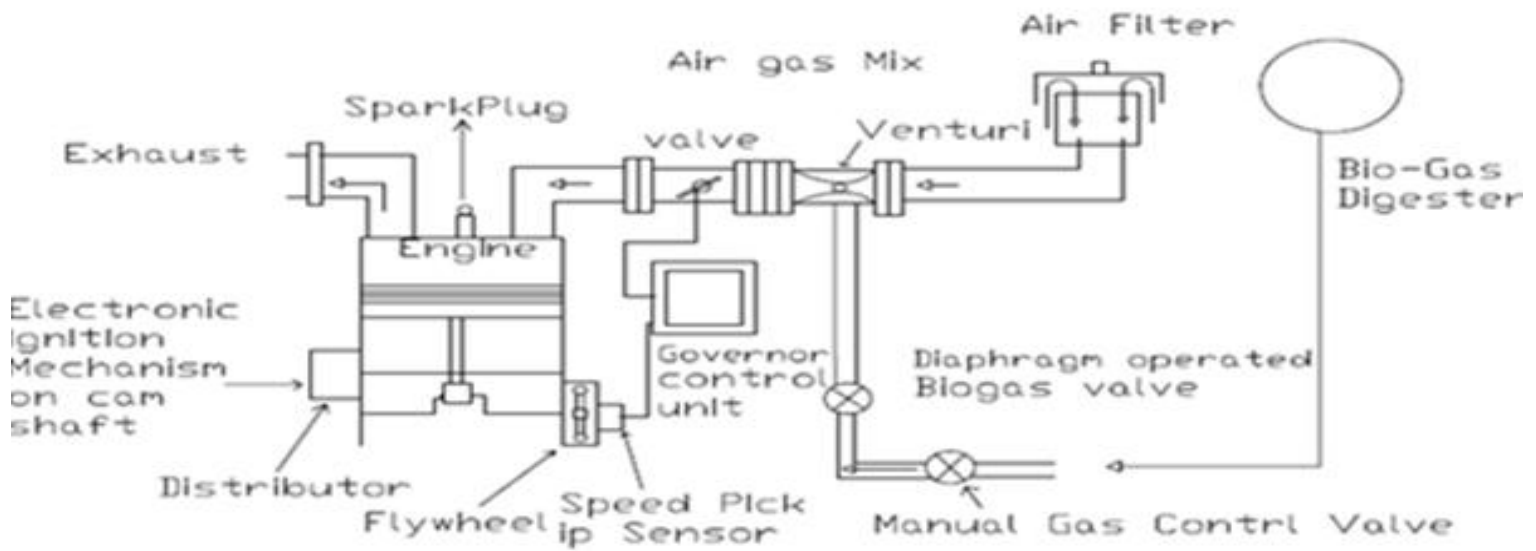

Fig. 2 Schematic diagram for conversion to biogas engine

\section{RESULT AND DISCUSSION}

Fig. 3 shows relation between variations of Brake power vs Engine speed. As engine speed increases brake power will be increases and Fig. 4 shows relation between Intake air and biogas mass flow vs engine speed

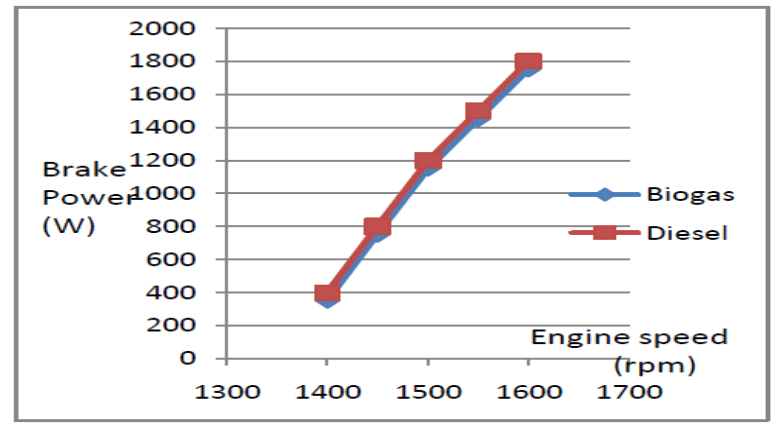

Fig.3 Variation of Brake Power vs. Engine Speed

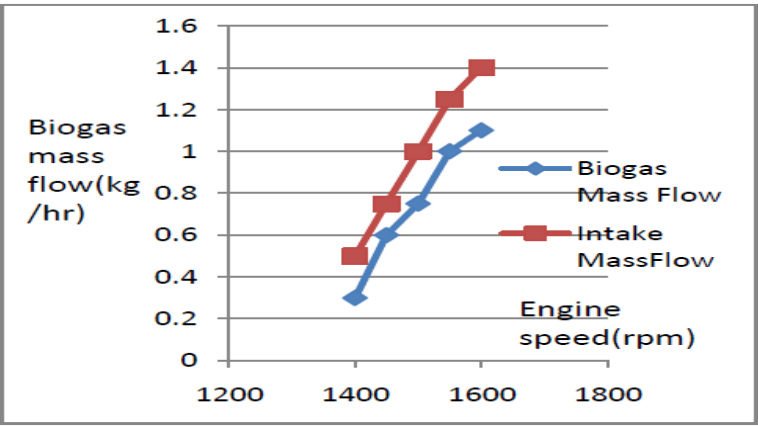

Fig. 4 Intake air and biogas mass flow vs engine speed

Fig. 5 shows relation between Intake air and diesel mass flow vs engine speed and Fig. 6 shows relation between BSFC vs Engine speed. As engine speed increases brake specific fuel consumption for biogas engine increases and for diesel engine decrease.

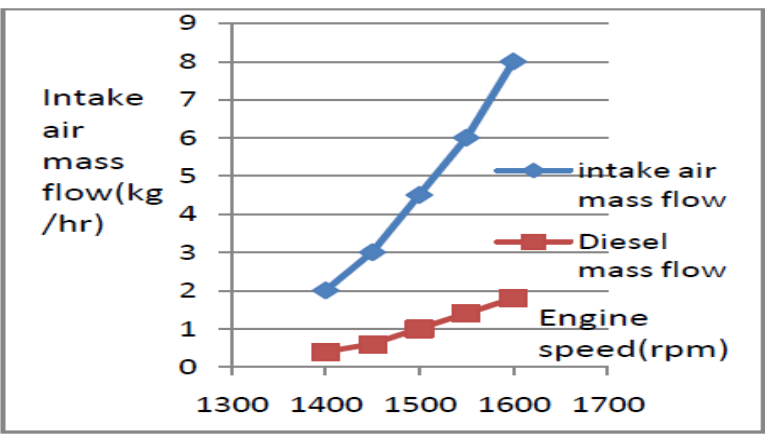

Fig.5 Intake air and diesel mass flow vs engine speed

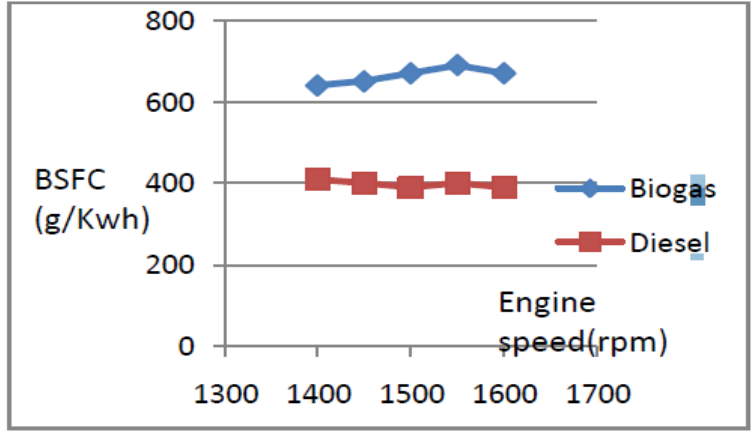

Fig.6 BSFC vs Engine speed

Fig.7 shows relation between Brake thermal efficiency vs Engine speed. As engine speed increases Brake thermal efficiency for biogas engine slightly increases and for diesel engine decrease. Fig. 8 shows relation Mech. Efficiency vs Brake thermal efficiency. 


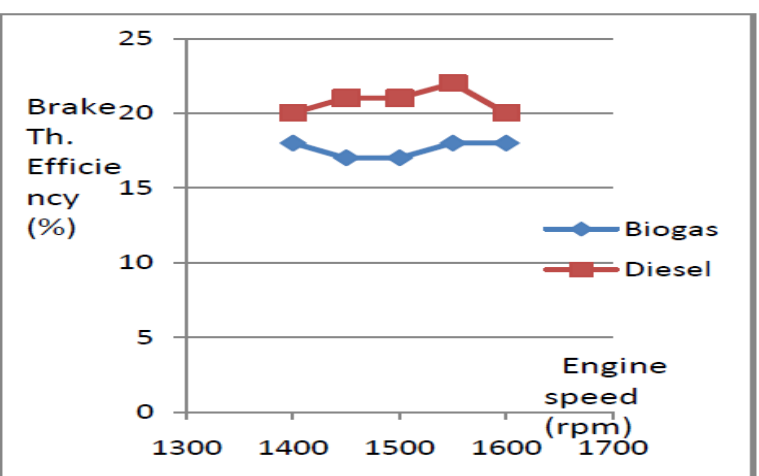

Fig. 7 Brake thermal efficiency vs Engine speed

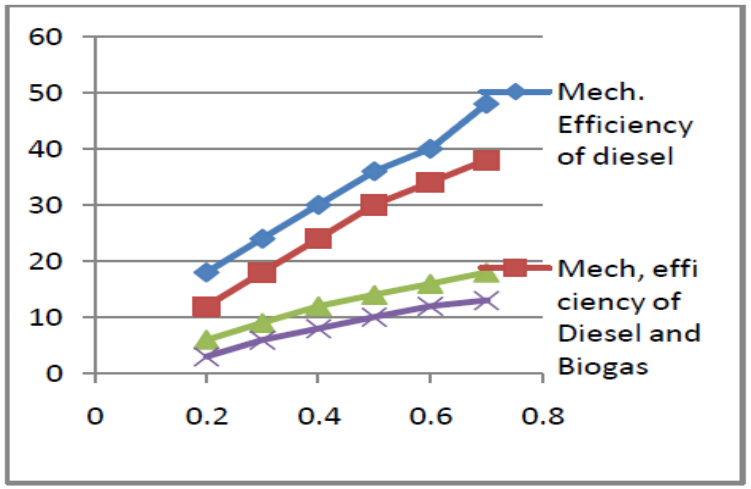

Fig.8 Mech. Efficiency vs Brake Th. Efficiency

\section{CONCLUSIONS}

1. Engine run well on $100 \%$ biogas. at low load condition.

2. Engine management, spark-ignition system and Venturi mixture will respond with engine load and speed.

3. $\mathrm{CO}_{2}$ emission will reduce on $100 \%$ biogas and contribution for developing rural economic and encourage local people enhance to the issue of energy and environmental pollution.

4. The Brake Specific Fuel Consumption increased as the percentage of biogas increased.

5. The Brake Thermal Efficiency is decreased as the percentage of biogas increased

6. By using biogas there is a reduction in $\mathrm{CO}$ emissions and $\mathrm{HC}$ emissions

7. The brake engine power decreases as the percentage of biogas increases

8. Conventional diesel fuel has higher brake engine power as compared to diesel and biogas.

\section{REFERENCES}

[1] J. Traino,S. Jiries, Biomethane: An economical and sustainable alternative vehicle fuel source, Bursic, 2014.

[2] Biogas to Biomethane technology review,Vienna University of Technology (AUSTRIA),Institute of Chemical Engineering, Research Divison Thermal Process Engineering and Simulation, May 2012

[3] A.J. Bruijstens, W.P.H. Beuman, M.v.d. Molen, J.d. Rijke, R.P.M. Cloudt, G. Kadijk, O.o.d. Camp, S. Bleuanus, TNO Automotive, Biogas composition and engine performance, including database and biogas property, Björn Hugosson, City of Stockholm Local Consortium Pierre Hirtzberger, January 2008

[4] Okobit, The biogas expert, Biogas plant, Fohren, Germany, 2011

[5] N. N. Dung, A Study of Conversion Diesel Engine to Fully Biogas Engine with Electronically Controlled, $\mathrm{Ho} C h i$ Minh City, Vietnam, December 2012.

[6] Biogas as Vehicle Fuel, Trendsetter Report No. 3, Stockhom, October 2003.

[7] N. Mustafi, R. R. Raine and P. K. Bansal, Biogas Fuel for Internal Combustion Engines, Department of Mechanical Engineering, The University of Auckland, 2006.

[8] Renewable energy in the U.S. biogas, Swidish Trade Council, U.S., January 2008.

[9] D. Barik, S. Sah, S. Murugan, Biogas production and storage for fueling internal combustion engines, National Institute of Technology, Rourkela, India, Feb 2013.

[10] N.H.S.Ray, P.R.Swain, M.K.Mohanty, An investigation on performance characteristics of C.I engine using biogas and diesel in dual fuel mode, CEB, BBSR, Odisha, June 2014

[11] H. S. Sorathia, H. J.Yadav, Energy analyses to a ci-engine using diesel and bio-gas dual fuel- A review study, Government Engineering College, Bhuj - Kutch, Gujarat, 2012 